\title{
2011 年度化学科学三处国家自然科学基金项目评审工作总结
}

\author{
魏学锋 ${ }^{1}$ 高飞雪 ${ }^{2}$ 杨俊林 ${ }^{2, *}$ \\ ('河南科技大学, 河南 洛阳 471003; ${ }^{2}$ 国家自然科学基金委员会化学科学部, 北京 100085)
}

\begin{abstract}
摘要: 主要总结了 2011 年度化学科学三处的面上项目、青年科学基金和地区科学基金项目的申请和资助情 况, 其中包括申请和资助项目的研究方向、依托单位分布以及项目申请队伍情况, 提出了值得注意的问题, 以期 为项目申请人和同行评议专家提供参考.
\end{abstract}

关键词：2011年度；化学科学三处；国家自然科学基金；项目评审 中图分类号: 064

\section{1 引言}

近几年, 物理化学和理论化学学科在基础研究 方面呈现良好的发展态势, 国家自然科学基金申请 量持续增长, 取得丰硕成果的项目逐年增加, 同时, 与其他学科具有交叉内容的项目也逐年增多, 2011 年度化学科学三处申请项目数继续保持稳步增长 的势头.

每年, 面上项目、青年科学基金和地区科学基 金的申请、资助量占绝大多数, 它们的申请、评审和 管理机制相同, 在激励创新、注重基础和前沿的科 学体系中发挥重要作用, ${ }^{1}$ 我们曾总结了 2005-2009 年物理化学和理论化学学科面上项目、青年科学基 金、地区科学基金的申请和资助情况. ${ }^{2}$ 本文将简述 2011 年度该学科领域基金申请与资助概况.

\section{2 项目申请和资助概况}

\section{1 申请和资助数量}

2011 年度化学科学三处面上项目、青年科学基 金、地区科学基金申请和资助情况见表 1 , 为便于比 较, 将2010年度的情况一并列出.

从表 1 可以看出, 2011 年度面上项目、青年科学
基金、地区科学基金申请数量仍然呈明显的增长趋 势, 三类项目共申请 2059 项, 较 2010 年的 1687 项, 增加了 372 项, 总的增长率为 $22.1 \%$. 其中面上项目 申请数增加了 100 项, 增长率为 $10.4 \%$, 低于 2010 年 的 $15.6 \%$, 与前五年的增长幅度相近; 青年科学基金 继续保持强劲的增长势头, 增长率为 $37.9 \%$, 高于 2010 年的 $28.8 \%$, 同时也高于 2005-2009五年的平 均增长率(34\%); 地区科学基金项目亦有较大的增 长.

从资助数量来看, 2011 年面上项目、青年科学 基金、地区科学基金共资助 535 项, 较 2010 年的 422 项, 增长了 $26.8 \%$, 资助率略有增长.

\section{2 对应学科申请代码申请和资助分布情况}

2011 年度申请和资助项目按学科申请代码分 布情况见表 2. 从表 2 可以看出, 2011 年度面上项目 申请中, 催化化学和电化学仍然为最活跃的申请领 域, 分别占申请量的 27.2\% (289/1064)和 20.8\%, 理 论化学和胶体化学也占较大比重, 分别为 $14.1 \%$ 和 $14.0 \%$, 结构化学约占 $10 \%$, 其他研究方向所占比例 相对较小.

青年科学基金的申请中, 催化化学和电化学与

表 12011 和 2010 年度面上项目、青年科学基金地区科学基金申请和资助情况

\begin{tabular}{|c|c|c|c|c|c|c|c|c|c|}
\hline & \multicolumn{3}{|c|}{ 面上项目/项 } & \multicolumn{3}{|c|}{ 青年科学基金/项 } & \multicolumn{3}{|c|}{ 地区科学基金/项 } \\
\hline & 申请 & 资助 & 资助率 ${ }^{* *} / \%$ & 申请 & 资助 & 资助率 $/ \%$ & 申请 & 资助 & 资助率 ${ }^{* *} / \%$ \\
\hline $2011\left(\%^{*}\right)$ & $1064(10.4)$ & $268+6^{\$}$ & 25.8 & 895 (37.9) & 236 & 26.4 & $100(35.1)$ & $24+1^{\$}$ & 25.0 \\
\hline $2010\left(\%^{*}\right)$ & 964 (15.6) & $232+10^{\$}$ & 25.1 & $649(28.8)$ & 163 & 25.1 & $74(29.8)$ & $15+2^{\$}$ & 23.0 \\
\hline
\end{tabular}

Received: August 18, 2011; Revised: August 19, 2011; Published on Web: August 22, 2011.

"Corresponding author. Email: yangjl@nsfc.gov.cn; Tel: +86-10-62327172. 
表2 2011 年度面上项目、青年科学基金、地区科学基金按学科代码分类

\begin{tabular}{|c|c|c|c|c|c|c|}
\hline & \multicolumn{2}{|c|}{ 面上项目/项 } & \multicolumn{2}{|c|}{ 青年科学基金/项 } & \multicolumn{2}{|c|}{ 地区科学基金/项 } \\
\hline & 申请 & 资助 & 申请 & 资助 & 申请 & 资助 \\
\hline B0301 结构化学 & 104 & 34 & 85 & 25 & 9 & 3 \\
\hline B0302 理论和计算化学 & 150 & 44 & 175 & 49 & 13 & 1 \\
\hline B0303 催化化学 & 289 & 67 & 249 & 61 & 27 & 7 \\
\hline B0304化学动力学 & 25 & 14 & 17 & 8 & 1 & 0 \\
\hline B0305 胶体与界面化学 & 149 & 29 & 93 & 29 & 15 & 5 \\
\hline B0306电化学 & 221 & 43 & 199 & 34 & 29 & 7 \\
\hline B0307光化学和辐射化学 & 37 & 12 & 31 & 11 & 1 & 0 \\
\hline B0308热力学 & 50 & 18 & 23 & 7 & 2 & 0 \\
\hline B0309生物物理化学 & 35 & 11 & 19 & 10 & 3 & 2 \\
\hline B0310化学信息学 & 4 & 2 & 4 & 2 & 0 & 0 \\
\hline
\end{tabular}

面上项目类似, 申请最多, 分别占申请量的 $27.8 \%$ 和 $22.2 \%$, 理论化学呈现增加势头, 占申请量的 $19.6 \%$, 胶体化学和结构化学分别占 $10.4 \%$ 和 $9.5 \%$, 其他研 究方向所占比例较小.

从资助率来看, 申请数量不多的化学动力学方 向资助比例最高, 面上项目和青年科学基金分别是 $56.0 \%$ 和 $47.1 \%$, 电化学方向资助率偏低, 连续多年 来低于平均资助率.

\section{3 依托单位分布情况}

将依托单位分为高校和科研院所两类, 各依托 单位类型面上项目、青年科学基金、地区科学基金 申请和资助项目总体情况见表 3 .

从表 3 可以看出, 申请单位由 2010 年的 365 家 增至 2011 年的 421 家, 增加了 56 家, 资助单位由 2010 年的 146 家增至 2011 年的 187 家, 增加了 41 家. 从资助率看, 科研院所资助率两年均高于高校, 超过 10 个百分点.

\section{3 项目分析与讨论}

\section{1 项目申请的质量}

\subsection{1 初篮情况}

2011 年度面上项目共初篮 7 项, 占面上项目申 请量的 $0.66 \%$, 青年科学基金和地区科学基金无初 管项目, 7 项被初篮的原因全是违反了项目指南中 的限项申请规定, 属超项申请.

\subsection{2 同行评议情况}

2011 年度面上项目、青年科学基金、地区科学
基金共发函 6156 份评议(每份申请有 3 位同行评议 人), 评议意见全部回收, 有效评议回收率 $100 \%$. 可 将评议结果按定量平均分统计, 如分别将优、良、 中、差定量为 $4 、 3 、 2 、 1$ 分, 则评议结果全为优的定量 平均分为 $4((4+4+4) / 3)$. 从同行评议结果来看, 面上 项目中, 有 $7.1 \%$ 的申请获得全优的评价, 略低于 2010 年的 $7.8 \%$, 略高于 2009 年的 $6.8 \%$, 有 $11.8 \%$ 的 申请获得 2 优 1 良的评价 (定量平均分为 3.67), $15.6 \%$ 的申请获得 1 优 2 良或 2 优 1 中 (定量平均分为 3.33 )的评价, $20.1 \%$ 的申请获得 3 个良或 1 优 1 良 1 中(定量平均分为 3 ) 的评价, 科学处按照计划资助项 目数的 $130 \%-150 \%$ 比例, 再考虑专家的资助意见, 初步确定学科评审组优先讨论的项目. 这样定量平 均分为 3.33 分以上且资助意见好的项目可初步列 入此类项目范围, 即其他项目列为非重点讨论项 目, 可以看出, 申请的总体质量较高, 竞争较为激烈.

青年科学基金中, 3.2\%获得全优的同行评议评 价, $9.5 \%$ 的申请获得 2 优 1 良的评价, $16.1 \%$ 的申请 获得 1 优 2 良或 2 优 1 中, $19.6 \%$ 的申请获得 3 个良或 1 优 1 良 1 中的评价. 相对于面上项目, 青年科学基 金优良率偏低. 在平均分为 3 分以上的 434 份申请 中, 资助意见中存在 1 个以上不予资助意见的申请 有 211 份, 由此可见, 青年科学基金同行评议的争议 较大.

在 100 份地区科学基金申请中, 有 3 份获得全 优评价得 4 分, 获 3.67 分的申请有 4 份, 获 3.33 分的 有 5 份, 获 3 分的有 19 份, 地区科学基金受地区经济

表3 面上项目、青年科学基金地区科学基金依托单位分布情况

\begin{tabular}{|c|c|c|c|c|c|c|c|c|c|c|}
\hline & \multicolumn{2}{|c|}{ 申请单位/所 } & \multicolumn{2}{|c|}{ 申请项目/项 } & \multicolumn{2}{|c|}{ 资助单位/所 } & \multicolumn{2}{|c|}{ 资助项目/项 } & \multicolumn{2}{|c|}{ 资助率 $/ \%$} \\
\hline & 高校 & 科研院所 & 高校 & 科研院所 & 高校 & 科研院所 & 高校 & 科研院所 & 高校 & 科研院所 \\
\hline 2011 & 372 & 49 & 1682 & 377 & 155 & 32 & 390 & 145 & 23.2 & 38.5 \\
\hline 2010 & 315 & 50 & 1395 & 292 & 120 & 26 & 317 & 105 & 22.7 & 36.0 \\
\hline
\end{tabular}


表4 面上项目、青年科学基金 地区科学基金申请队伍基本情况统计

\begin{tabular}{|c|c|c|c|c|c|c|}
\hline & \multicolumn{2}{|c|}{ 面上项目 } & \multicolumn{2}{|c|}{ 青年科学基金 } & \multicolumn{2}{|c|}{ 地区科学基金 } \\
\hline & 申请 & 资助 & 申请 & 资助 & 申请 & 资助 \\
\hline 博士学位比例/\% & 93.4 & 93.4 & 92.8 & 97.9 & 74.0 & 92.0 \\
\hline 正高职称比例/\% & 52.9 & 71.5 & 2.5 & 7.2 & 51.0 & 52.0 \\
\hline 副高职称比例/\% & 43.5 & 27.0 & 35.1 & 37.8 & 40.0 & 40.0 \\
\hline 中级(以下)职称比例/\% & 3.6 & 1.5 & 62.4 & 55.0 & 9.0 & 8.0 \\
\hline 45 岁以下比例 $/ \%$ & 66.2 & 60.2 & - & - & 60.0 & 80.0 \\
\hline
\end{tabular}

相对落后、人才队伍力量相对薄弱等因素的影响, 总体质量有待继续提高.

\subsection{3 质量评估}

2011 年度面上项目申请中, 粗略地分析可发 现, $2.2 \%$ 的申请有一定的原始创新性, $31.2 \%$ 具有跟 踪创新性, 与生命、能源、环境和材料等领域交叉的 申请占 $6.7 \%$; 青年科学基金申请中有 $38.1 \%$ 为跟踪 创新项目, 相当一部分申请没有明显创新, 交叉领 域的项目占申请量的 $6.9 \%$; 地区科学基金申请中, 跟踪创新申请占 $31.0 \%$, 交叉领域申请占 $7.0 \%$.

\section{2 项目申请队伍特征统计}

2011 年度面上项目、青年科学基金、地区科学基 金申请和资助项目负责人的学位、职称、年龄情况结 果见表 4 .

从表 4 可以看出, 在全部申请项目中, 面上项目 和青年科学基金的申请人具有博士学位的比例在 $90 \%$ 以上, 地区科学基金的申请人具有博士学位的 比例相对偏低, 也反映了地区科研队伍力量相对较 弱.

在获得资助项目中, 面上项目、青年科学基金、 地区科学基金负责人获得博士学位比例均超过 $90 \%$. 其中, 面上项目申请和资助项目中具有博士学 位比例一致, 反映出申请人的自身科学素质在是否 能获得资助中的重要性; 青年科学基金获资助项目 的负责人具有博士学位的比例高达 $97.9 \%$, 可见博 士阶段受到良好的科研训练从而保证了他们独立 从事科研的能力; 地区科学基金负责人博士学位比 例明显高于申请中的比例.

从职称情况来看, 面上项目申请人和获资助者 绝大多数具有副高以上职称, 资助者中正高职称的 比例明显高于申请中的比例. 青年科学基金受年龄 和履历的影响, 正高职称的比例较小, 副高职称在 申请和资助中都占三成以上, 多数为中级职称. 地 区科学基金申请和资助职称比例基本相同,正高职 称约占一半, 副高职称占四成.

从年龄看, 面上项目申请人和获资助者在 45 岁
以下的比例接近三分之二, 可看出本学科科研队伍 年龄结构合理. 地区科学基金年龄在 45 岁以下的申 请人和获资助者分别占 $60 \%$ 和 $80 \%$, 反映了更多的 年轻科学家扎根于相对较落后的地区, 在科研岗位 上潜心工作.

\section{3 女性科学工作者申请和资助情况}

2011 年度, 在 895 位青年科学基金申请人中有 427 位女性(占 47.7\%), 其中年龄在 36-40岁之间的 有 100 位(从 2011 年开始, 青年科学基金女性申请人 的年龄限制由未满 35 周岁推迟至未满 40 周岁), 在 236 位获资助的项目负责人中有 99 位女性 (占 $41.9 \%$ ), 其中年龄在 36-40 岁之间的有 28 位; 面上 项目申请和资助的项目中女性的比例分别为 $22.5 \%$ 和 18.2\%, 地区科学基金申请和资助的项目中女性 的比例分别为 $25.0 \%$ 和 $24.0 \%$.

\section{4 几点说明和建议}

\section{1 资助金额和期限}

2011 年度化学科学三处面上项目平均资助强 度为 61.1 万元/项, 青年科学基金平均资助强度为 25.1 万元/项, 地区科学基金平均资助强度为 52.1 万 元/项. 根据申请指南, 面上项目及地区科学基金的 资助期限从 2011 年开始改为 4 年. 我处 2011 年面上 项目和地区科学基金中的小额探索项目资助期限 为 2 年, 资助强度分别为 30 万元/项和 25 万元/项.

\section{2 重点项目情况}

2011 年收到重点项目申请 52 项, 初筛 3 项, 49 项有效申请项目涉及发布指南中的全部 12 个领域, 根据同行评议结果, 科学处推荐 14 个项目参加答 辩. 其中, 申请数相对较多的四个领域情况为, 针对 理论与计算化学在能源、环境或生命领域中的应用 方向申请最多(11 项), 科学处根据同行评议结果推 荐 3 项参加答辩; 催化材料的催化作用本质领域的 申请为 8 项, 推荐答辩 1 项; 能源转化与储存中的关 键物理化学问题领域的申请为 8 项, 同行评议结果 整体较差, 该领域没有推荐项目参加答辩; 碳资源 
优化利用中的关键物理化学问题领域申请 7 项, 1 项 推荐答辩. 通过答辩, 专家组投票遴选 11 项获资助, 平均资助强度为 300 万元/项.

鉴于上述事实, 学科评审会讨论 2012 年重点项 目的项目指南时, 充分考虑了 2011 年度重点项目的 申请和资助情况.

\section{3 申请中存在的问题}

在申请量逐年递增的同时, 申请书的质量有一 定程度的提高, 研究内容有特色的项目数增多, 绝 大多数申请能很好地阐明相关研究的工作基础、研 究思路、研究路线和创新思想. 但也存在一些问题:

(i) 少数申请人连续多次申请, 但申请书无明显 修改, 原封不动地重复提交; 有一些申请书存在打 字输入错误较多的现象.

(ii) 基础研究的关键是科学问题的凝练, 解决 科学问题的思路往往体现申请人的创新思想, 一份 申请书的灵魂所在是在相关文献及前人工作的基 础上凝练出到位的科学问题. 因此, 同行评价不高 的申请中, 同行评议意见多数为提出的科学问题比 较空洞, 泛泛而谈, 如笼统地说“探讨某某反应机 理”, “研究某某构效关系”等.

(iii) 研究方案往往是创新思路的具体体现, 有 少数申请存在研究方案不清晰, 使得同行评议专家 无法判断项目的可行性.

(iv) 一些申请尽管在较为充分的文献调研基础 上提出了恰当的科学问题. 但缺少相关方面的预 研, 容易使评审专家对项目是否能顺利完成有一定 的担心; 必要的科研条件是项目高质量完成的保
证, 青年工作者刚获得博士学位后, 来到新的工作 单位, 在学位论文基础上提出新的课题, 但设备条 件往往远远落后于原学习单位, 工作条件不够完 善, 这也可能成为项目不能获资助的原因.

\section{4 建 议}

(i) 申请人递交申请时要注重申请书提交学科 的本身特点, 对申报学科自身存在的基本科学问题 有较深的了解.

(ii) 随着自然科学基金受关注程度的日益提 高, 自然科学基金的资助情况也成为多数依托单位 科研管理部门绩效考核的重要指标, 建议各单位在 鼓励申报数量增加的同时, 关注申报的质量及获资 助的比例, 深刻分析未获资助的内在因素.

(iii) 自然科学基金工作的顺利开展长期得益于 广大同行评议专家的辛勤工作, 绝大多数评议人本 着对学科发展负责的态度, 给出了较为具体的修改 意见或需要注意的方面, 这些建议反馈给申请人 后, 会成为修改申请书的宝贵财富, 对他们提高工 作水平将大有帮助. 因此建议各位同行评议专家, 避免对资助项目的笼统地否定或提出诸如“创新性 不强”、“可行性分析不够”、“基础一般”等不清晰的 “八股”意见, 远远不能使申请人信服, 同时对进一 步提高申请书的质量作用甚微.

\section{References}

(1) 2011 年度国家自然科学基金项目指南.

(2) Gao, F. X.; Yang, J. L. Acta Phys. -Chim. Sin. 2009, 25 (10), 2173. [高飞雪, 杨俊林. 物理化学学报, 2009, 25 (10), 2173.] 